Title: Surviving the world of academia: A brief commentary on strategies for success; SF; October 22, 2013

\title{
Background
}

Academia is an environment in which teaching, research, and the pursuit of scholarship are characterized. ${ }^{1}$ It is routinely described as embodying an atmosphere of isolation, yet is highly competitive. Extreme sacrifices seem to be forefront and centre. Individuals are routinely asked to take on increasingly heavy teaching workloads, while at the same time are expected to produce a significant number of publications, in unison with obtaining external funding. The nature of academia has not always faired well for new scholars. This paper presents a discussion of various strategies new academics or those considering pursuing this arena can use to assist in not only the transition to working in this environment, but also thriving in it. It will provide an awareness of the lessons learned and an anticipation of the future from a scholar who has overcome the initial barriers and is optimistically looking forward to future challenges.

$$
\text { Publish, publish, publish }
$$

The first year as an academic can be daunting. The pressures of needing to be amalgamated quickly into a new role; becoming familiar with the techniques and nuisances associated with teaching, designing courses; as well as interacting with students can be overwhelming to say the least. Added to these stressors is the continued need to have an active and productive program of research. As a new scholar, one may not have had an opportunity to clearly articulate their program of research and thus may not have any research studies underway. Knowing that teaching is an integral part of one's life as a scholar, a good portion of one's first year should focus on developing their abilities to engage students in the classroom, refine their knowledge of course content, and enhance their skills related to marking and providing feedback. This is not to say that research should be cast aside. On the contrary, significant amount of 
reflection should occur throughout this period as to what studies have already been completed and what future studies need to be designed and implemented. This introspective reflection will guide the development of ideas for future projects. Keep notes of all ideas as they are generated.

The formulation of ideas and thoughtful reflection are key to the research process, but they are not valued at the time of evaluation. It is the tangible outputs such as the number and quality of publications that are counted, and upon which year-end evaluations are based. Thus, as you are reflecting on ideas for future projects, keep a list of ideas for manuscripts as well. During the first year, you should aim to publish as much as you can. Typically, a portion of an academic's time is partitioned off for research endeavors. This may be a day or in some cases 2 days. Whatever day or hours that you have identified as research time, block this period off and focus only on research related activities. During this time, you should aim to write as much as possible.

Many new scholars will argue that it is difficult for them to write, as they may not have results from a study readily available to write about. I would reason that you don't need results to write a manuscript. There are many types of papers that can be written such as: clinically based articles, case studies, practice/service development or innovation focused papers, theoretical perspectives, policy reports, discursive analyses, commentaries, and educational viewpoints. As an academic, you were hired because you have a unique knowledge base and are able to critically examine concepts, thus you are in an ideal position to write about almost anything. The more you reflect on your research endeavors, the easier it becomes to write and generate ideas for future projects.

As you write, ensure that your manuscripts fall within a defined area. Try to be as consistent as possible with the overall theme of your manuscript. Ensure that you're focus is reflective of your program of research. Your goal, as with any scholar; should be to develop expertise is a particular area of interest. You should ask yourself, what is it that I want to be known for? Your response 
should ideally be limited to one area at the most. However, it is not unusual to encounter scholars who have developed a program of research around 2 very different themes.

Rejection is very common in the world of academia. It is extremely rare for a paper to be accepted without any revisions. Having a manuscript rejected is not the be all and end all in academia. You will encounter many, many rejections throughout your life as a scholar. These are not personal evaluations of you and should not be dwelled upon. Instead, use the feedback obtained from the reviewers to revise the manuscript and resend to another journal. Revise and resubmit as much as you feel you need to.

\section{External funds}

Acquiring external funding is another parameter upon which scholars are evaluated. Unfortunately, failure to obtain external funding has become the basis of frustration and anguish for many scholars. The recent economic downturn has made an already competitive arena, that much more competitive. Large government funded organizations present estimates of 1 out of every 10 submissions an applicant put forwards as having received funding (http://www.cihrirsc.gc.ca/e/44787.html). Thus, this means having to deal with 9 different rejections over a number of months or even years, before obtaining an externally funded national grant. This may be daunting to many. However, there should be some comfort in knowing that in time, with dedicated effort, the creation of research proposals does get much easier. A helpful technique when revising proposals is to use the feedback obtained from reviewers and edit according to suggestions that were put forth. This increases your chances of getting funded. As well, the more publications you have, the better your chances are of obtaining an external grant; as this indicates that you have developed a very thorough knowledge base of your program of research. 
Focus is the key to success in academia. You need to delineate clear, achievable goals with realistic timelines and maintain consistent focus as you address each goal. At the start of each semester, specific goals should be identified and placed within close proximity of your usual workstation. Present the goals in large bold font, along with manageable timelines. As you work though achieving each goal, delete them from your list. To assist in attaining the goals identified, you need to be focused. Without dedication and attention to achieving identified goals, you will not be able to progress within the realm of academia. If, for example you identified the submission of 2 manuscripts for review over the course of a semester; then you should use the days that you have blocked off for involvement in research, to work on these manuscripts. Meetings with students, marking of assignments, and engagement in professional activities should not occur on this particular day.

\section{Networking and other activities}

Joining research forums, attending professional development lectures and workshops, and even creating a research cluster will assist in the formation of formidable research partnerships. It is challenging to write on one's own and in many instances it is not recommended that researchers apply for grants independent of co-investigators. Thus, working with your colleagues both within and outside of academia can be fruitful and prove to be beneficial to all parties involved. Finally, accept invitations to serve as a peer reviewer. This will provide you with further insight as to peer review evaluation procedures, how to give constructive feedback, and to keep abreast of current innovative techniques within your area of interest. 


\section{Reference}

1. Seggie S, Griffith DA. What does it take to get promoted in marketing academia? Understanding exceptional publication productivity in the leading marketing journals. $J$ of Marketing, 2009; 73:122132.

This manuscript was published by HealthCom Media, Fredericks, S. (February, 2014). Surviving the World of Academia: A brief commentary on strategies for success. American Nurse Today. Vol. 9 No. 2. http://www. americannursetoday.com/Article.aspx?id=11226\&fid=11176\#comments 